\title{
Does Designing Environmental Sustainability Disclosure Quality Measures make a difference?
}

\author{
Akrum Helfaya ${ }^{1}$ \\ Accounting Department, \\ Keele University, United Kingdom \& \\ Damanhour University, Egypt \\ a.n.ekara.helfaya@keele.ac.uk
}

\section{Mark Whittington}

Accounting \& Finance Department, University of Aberdeen, United Kingdom mark.whittington@abdn.ac.uk

This is the final peer reviewed version of the following paper: [Helfaya, A., \& Whittington, M. (2018). Does Designing Environmental Sustainability Disclosure Quality Measures make a difference? Business Strategy and the Environment], which has been published in final form at [DOI: 10.1002/bse.2262]. This paper may be used for non-commercial purposes in accordance with John Wiley \& Sons, Ltd and ERP Environment terms and conditions for self-archiving.

\footnotetext{
${ }^{1}$ Corresponding author
} 


\section{Abstract}

Assessing the quality of information disclosed by companies is a complex task. Accounting studies usually rely on analysing the content of corporate reports using measures to obtain a proxy for the information reported by companies. However, there is no consensus about the best design for these measures. The objective of the current paper is to investigate if there are significant differences in the results generated from seven alternative measures for assessing the quality of FTSE100 environmental sustainability reporting. Seven measures/indices have been used to assess disclosure quality. The three uni-dimensional measures include two "Quantity measures" and one "Scope measure" that measure the volume and width/coverage of information respectively. Three compound measures are adopted from the literature (Al- Tuwaijri et al. (2004); van Staden and Hooks (2007), and Beretta and Bozzolan (2008), and the final measure is a multi-dimensional quality model, based on the results of a questionnaire ascertaining the perceptions of 86 preparers and 177 users of annual report (AR) and/stand-alone corporate responsibility report (CRR). While the results of the empirical analysis indicate that the measures are significantly correlated, the choice of a specific method can result in the very different ranking of companies. The evidence presented indicates that the choice of measure is of key importance.

KEY WORDS: Disclosure research; disclosure quality measures; disclosure index; environmental sustainability information; UK FTSE100. 


\section{Introduction}

At the end of book one of Wealth of Nations, Adam Smith (1776) discusses the complex interweaving of three great orders of civilised society: landowners, employees and employers. He then writes of employers as:

"... an order of men, whose interest is never exactly the same with that of the public, who have generally an interest to deceive and even to oppress the public..." (location 4807).

Smith thus introduces the idea that employers should be treated with suspicion. Bowen (1953) also recognises the power of the employer, or corporation, and seeks to answer two key questions of whether their power-advantage came with broader responsibility:

"Are businessmen, by virtue of their strategic position and their considerable decision-making power, obligated to consider social consequences when making their private decisions? If so, do they have social responsibilities that transcend obligations to owners or stockholders?" (p.4).

Friedman (1962) counters this view with one that sees the task of the corporate manager as simply maximising profit for shareholders only subject to any legal constraints rather than broader concerns for other stakeholders or for society as a whole. Such burdens on management he saw as an inappropriate tax on the shareholders. Jensen (2002) and others have noted the logical truth that maximisation for one stakeholder group will by necessity lead to a sub-optimal outcome for others. The complexity of recognising and defining the social responsibility of corporations has led to many different theories, which seek to view the issue through differing lenses and academic starting points (Garriga and Mele, 2004) with some, for example, seeking perhaps pragmatic integration of profit and social objectives whilst others undertake a more ethics-based discussion.

Once a view has been taken that there needs to be more accountability than just shareholderfocused performance measurement, at least three further questions then arise. The first addresses which additional stakeholders might be seen as legitimate and accorded due regard in the management of the firm, with Phillips (2003), as one example, discussing stakeholders and "non-stakeholders" (see chapter 6), though the corporation is seen as having a moral obligation to even non-stakeholders "as humans" (p.130). The second is whether this wider responsibility should be for all corporates or just certain categories, for example Looser and Wehrmeyer (2015) address the motivations of large versus small companies. The third, and our area of interest here, is how should performance measurement 
for other recognised stakeholders be assessed and reported. Such discussions have become a significant element in accounting research, as well as a more general management concern. Such literature has developed both empirically and theoretically as well as developing subthemes, for example, social and environmental reporting. It has also developed a degree of introspection (see for example, Gray, 2006) questioning the purpose and delivery of the implied social benefits of corporates seemingly being held to account.

Extant corporate social and environmental responsibility (CSR) reporting literature has researched who is reporting, what is reported and how much is reported (e.g., Ben-Amar and Chelli, 2018; Burritt and Christ, 2017; Campbell et al., 2003; Hassan, 2018; Gurthrie and Parker, 1990; Gray et al., 1995; Lee, 2017; Lokuwaduge and Heenetigala, 2017; Meng et al., 2014; Radu and Francoeur, 2017; Tian et al., 2016). Additionally the style of content in annual reports (ARs), the use of narrative, graphs, and more recently images, have provided a basis for not just assessing the amount of disclosure but also the readability and reporting quality (Beattie and Jones, 1992 \& 2001; Jones and Shoemaker, 1994). Although report content, scope, and visual design have provided a basis for measuring the quality of CSR reporting, to date most prior research has looked simply at the volume or the type of disclosures made in assessing the quality of the stand-alone corporate responsibility report (CRR) (Haque and Ntim, 2018; Lee, 2017; Kalu et al., 2016). Dominant among the research methods used are content analysis, whether assessed by word, sentence or page counts, readability measures, or proportional analysis of good/bad news. Normally, such research uses quantitative measures to draw statistical inferences about the quality of CSR reporting (e.g. Wisman, 1982; Hackston and Milne, 1996; Tom, 2002; Cormier et al., 2005; Hasseldine et al., 2005; Brammer and Pavelin, 2008). This is based on the assumption that quantity of disclosure also captures the quality or transparency of disclosure. However, better conclusions may be achieved if a disclosure measure is designed that directly measures quality, as quality may not be synonymous with quantity (D'Amico et al., 2016; Hassan, 2018; Helfaya et al., 2018; Radu and Francoeur, 2017).

Recognising the fact that robust, reliable, and replicable quality assessment is problematic (Ben-Amar and Chelli, 2018; D’Amico et al., 2016; Helfaya et al., 2018; Lee, 2017; Michelon et al., 2015; Radu and Francoeur, 2017), this research aims to investigate if there are significant differences among the quality measures used in prior corporate reporting studies. Seven measures/indices used to assess the disclosure quality of the FTSE100 
environmental sustainability disclosure are compared. Based on the complexity and dimensional nature of these measures, the current study classifies these measures into two groups; uni-dimensional measures or compound/multi-dimensional measures. Unidimensional measures include two "Quantity measures" that measures information disclosed exclusively in terms of quantity and one "Scope measure" that measures the width/coverage of information are used. Four compound measures are also used to assess the quality of FTSE100 environmental sustainability disclosure. Three of these are adopted from the literature: the disclosure scoring technique (ACHI) designed and used by Al- Tuwaijri et al. (2004); the quality index of environmental disclosure (SHI) developed by van Staden and Hooks (2007), and the total quality index (TQLI) designed by Beretta and Bozzolan (2008). Additionally, a multi-dimensional quality model (MQM), the fourth measure, developed by Helfaya et al. (2018), is based on the results of a questionnaire ascertaining the quality perceptions of both preparers and users of ARs and CRRs.

Consequently, this paper makes several contributions to the disclosure quality literature. First, to best of our knowledge, this is the first study to use both simple and compound measures to assess the quality of environmental sustainability disclosure and to test if the design of the quality measure make a difference or not. As Hopwood (2009, p. 437) clarifies that since "it is possible for some modes of reporting to thicken that veil such as even less is known of the corporation despite the apparent openness of its reporting”, it is essential to focus also on the semantic characteristics and the meaning of information disclosed to provide a comprehensive picture of corporate disclosure behaviours. Therefore, we used recent quality measures/indices (Al-Tuwaijri et al., 2004; Beretta and Bozzolan, 2008; Helfaya et al., 2018; Meng et al., 2014; Michelon et al., 2015; van Staden and Hooks, 2007) to assess the different dimensions of disclosure quality and to compare the quality scores produced by these measures. Our findings proved that quality disclosure is a multidimensional concept, which covers quantity, content, credibility, and presentation.

Second, this research provides methodological evidence that both design of the quality measure and the coverage of different quality dimensions have a significant impact on the quality scores and rankings of companies. This evidence is aligned with previous studies that argue that the design of the quality measure affects the quality scores (Beattie et al., 2004; Beretta and Bozzolan, 2008; Urquiza et al., 2009). Third, this study sheds light on the effect of the use of multi-dimensional measures (e.g., TQLI and MQM) on assessing the 
quality of disclosure. However, both produced different quality scores. We argue that the less subjective MQM that covers a wide range of quality features is the best measure of disclosure quality (Beretta and Bozzolan, 2008; Helfaya et al., 2018).

Fourth, the findings of this research have several implications for a number of constituencies, including the targeted audience of Business Strategy and the Environment. For corporate reporters and readers of environmental performance information, our results support earlier recommendations in environmental sustainability disclosure literature that the quality of reporting is a multifaceted concept covering many features, such as quality of content, credible content using reporting guidelines and assurance services as well as readable content using visual tools (e.g. D'Amico et al., 2016; Helfaya et al., 2018; Helfaya and Kotb, 2016; Michelon et al., 2015). For policy-makers, standard setters and environmentalists, our results shed light on the importance of the credibility of environmental sustainability disclosure by, for example, adopting reporting guidelines such as GRI and engaging third-party assurance (see, Haque and Ntim, 2018; Helfaya et al., 2018). In practice, there is a trust gap between environmental sustainability reporters and users. To decrease this gap, policy-makers, standard setters and environmentalists need to set a commonly agreed set of CSR reporting guidelines and assurance standards. The standard setters and environmentalists might then also have the legitimacy to ensure that a company's management and report writers complied with such reporting framework requirements. For corporate sustainability scholars and environmentalists, the MQM used in this study could be used to conduct future investigations of assessing the quality of corporate environmental sustainability disclosure.

This paper is structured as follows. The next section summarises the literature, while section three presents the research methodology. The results are presented in section four, followed by a discussion and conclusion.

\section{Literature review}

\section{Definition and Measurement of Quality}

'Quality' is a key concept in many fields of research such as; quality of life, quality of food, water, and air, quality of service provision, quality of accounting disclosure, etc. In all fields, defining quality is judgement based and potentially even a political position. For 
example, the International Accounting Standards Board (IASB) states that their 2018 conceptual framework contributes to its mission to:

"develop standards that bring transparency, accountability and efficiency to financial markets around the world" (SP1.5, page 6. IASB, 2018)

One could assume, therefore, that the IASB would define quality for financial reporting, if not implicitly for all reporting, as focused on the needs of the investors as primary stakeholders. Each stakeholder group, customers, employees etc., will have differing perceptions, aims and information requirements which may be more or less consciously developed. One stakeholder's needs may be thought irrelevant to another, or even conflicting in perception as good or bad. For example, excellent clarity on bad environmental incidents may be perceived as useful and good to consumers, but undesirable to managers and shareholders who might benefit from a lack of awareness. Quality is concerned with fitness for purpose and stakeholders with differing purposes are unlikely to be always of one mind regarding the working out of the concept in practice.

The accounting reporting literature is aware of the complexity and subjectivity nature of this notion (Beattie et al., 2004; Ben-Amar and Chelli, 2018; D'Amico et al., 2016; Kalu et al., 2016; Lee, 2017; Lokuwaduge and Heenetigala, 2017; Meng et al., 2014; Radu and Francoeur, 2017). Such literature also argues that to acquire a rich understanding of reporting and disclosure quality, it is necessary to focus on the individual dimensions of quality (e.g., quantity, breadth, depth, and time). Consequently, the amount of disclosure (the most frequent metric in the historic literature) is only one quality dimension. Indeed, a host of scholars note that it is often incorrectly assumed that the importance of a disclosure can be meaningfully stand for the amount disclosed (see, Cho et al., 2010; Gray et al., 1995; D'Amico et al., 2016; Unerman, 2000). In practice, prior studies have advanced to include more dimensions to assess disclosure quality based on the characteristics of information disclosed volume disclosed, themes/topics covered, types of information, and the language used in disclosure. In most cases (about $80 \%$ of corporate environmental reporting research), the "quality" is measured using a simple model including only one or two dimensions. As quality is subjective and context-dependent, we need a comprehensive descriptive model (compound model) to assess quality (e.g., the range of themes addressed, the measures of disclosure, time-period, and credibility of disclosure, etc.). 
So, quality, even in the environmental reporting field, is a complex concept, and has a multifaceted and subjective nature (Beattie, et al., 2004; Beck et al., 2010; D’Amico et al., 2016; Hammond and Miles, 2004; Lokuwaduge and Heenetigala, 2017; Meng et al., 2014; Radu and Francoeur, 2017). One of the most important limitations encountered in disclosure studies is the difficulty of measuring the extent of corporate disclosure (Healy and Palepu, 2001). Volumetric approaches, on the one hand, which count words, sentences, or pages, are based upon the assumption that the volume of disclosure reflects its importance to the readers and so can be used as a measure of reporting quality (Helfaya et al., 2018). While the use of un-weighted disclosure indices, using more than one measure of quantity, to assess the quality of corporate disclosure is also problematic and has been criticised on its fundamental assumption that all disclosed and measured items are equally important. These approaches are also focussed only on how much is disclosed as a proxy for quality.

Meaning or interpretative approaches, on the other hand, such as weighted thematic content analysis has also been used to assess the quality of disclosure (Beck et al., 2010; Lee, 2017). These approaches have mainly assessed what is disclosed and how it is disclosed by analysing the content using specific criteria and then weighting/scoring these criteria based on the perceived relative importance of each item. These weighted disclosure index studies include, Tom, (2002), Cormier et al. (2005), van Staden and Hooks, (2007), and Meng et al. (2014). The use of a weighted disclosure index, however, has been criticised because it may reflect a bias towards a particular user-group (Helfaya et al., 2018). These weighted thematic content analysis studies seek to evaluate the content of specific disclosed topics, rather than merely counting them (Beck et al., 2010).

\section{Reliability of Measuring Quality}

Unerman (2000) discusses the disclosure of information using content analysis, an approach used to measure comparative positions and trends in corporate reporting (Guthrie et al., 2008; Kalu et al., 2016; Radu and Francoeur, 2017). They also state that content analysis is a technique for collecting information; it includes codifying qualitative and quantitative information into pre-determined categories and sub-categories to drive trends and patterns in the disclosure and reporting of information. This coding structure should carefully designed, otherwise it can produce misleading results (i.e., the validity of inferences drawn from data derived depends on the integrity of the content analysis and reliability of the data collected) (see, Lee, 2017; Milne and Adler, 1999). Further, if the scoring systems are awarded on the basis of disclosure/non-disclosure (i.e., unweighted disclosure index, a 1/0 scale), the 
evaluation of quality will be limited as this precludes assessment on themes covered, completeness, relevance, reliability, and other desirable qualities of corporate disclosure. In this vein, Krippendorff (2004) states that reliability is dependent upon the process employing shared meanings, creating the same referents independently of the coder (see, also, Kalu et al., 2016). Therefore, he defined three dimensions of reliability: a) stability: the extent to which the same coder is consistent over time when analysing the same content), b) reproducibility or inter-coder reliability: the extent to which different coders produce the same results when analysing the same content), and c) accuracy: the extent to which the classification of text corresponds to a standard or norm (Krippendorff, 2004). Lastly, the scoring system is value loaded and dependent upon the prior knowledge of coders/researchers (Hammond and miles, 2004). In practice, the consistency of measuring quality is difficult to achieve. Milne and Alder (1999) argue that a training session of around 20 reports in vital to accomplishing reliable results.

\section{Disclosure approaches: Assessing the quality of Environmental Disclosure}

The common disclosure approaches adopted by previous literature (e.g., Al-Tuwaijri et al., 2004; Cho et al., 2010; D’Amico et al., 2016; Hackston and Milne, 1996; Hassan, 2018; van Staden and Hooks, 2007) have been based primarily on a checklist of themes/topics that capture the volume and variety of disclosure. Most of the CSR studies have assessed CSR disclosure based on the amount of space allocated to the disclosure and number of themes disclosed. However, Michelon et al. (2015) state both the amount of disclosure and the themes of CSR disclosure are potentially important for corporate managers and report readers, they do not take into account other important dimensions/features that describe the information disclosed (see, also, Lee, 2017). Hence, these extant studies are not able to assess fully the quality of disclosure (see, Beretta and Bozzolan, 2008; Jizi, 2017; Kalu et al., 2016; Patten and Zhao, 2014; Urquiza et al., 2009; Radu and Francoeur, 2017).

Accordingly, a number of disclosure studies have developed that take traditional content analysis approaches (e.g., volumetric and interpretative) and scoring methods (e.g., unweighted and weighted disclosure index) and then seek to improve how the variety and multidimensionality of informational themes are captured and assessed (Al-Tuwaijri et al., 2004; Beattie et al., 2004; Beretta and Bozzolan, 2008; Helfaya and Kotb, 2016; Helfaya et al., 2018; Michelon et al., 2015; Meng et al., 2014). For example, Michelon et al. (2015) assessed the quality of CSR disclosure using the Beretta and Bozzolan (2008) quality model. 
They assessed the quality of disclosure by capturing both quantity of information disclosed and the "richness" of disclosed content. This richness capture a great number of quantitative and qualitative features of a specific type of disclosure. Most recently, Helfaya et al. (2018) developed a multinational quality model (MQM) to assess the quality of environmental disclosure. In contrast to previous studies which developed and used a subjective authorbased approach for assessing the quality of corporate disclosure (e.g., Al-Tuwaijri et al., 2004; Berretta and Bozzolan, 2008; Michelon et al., 2015; Patten and Zaho, 2014; van Staden and Hooks, 2007), Helfaya et al. (2018) sought to develop a less subjective MQM which goes beyond the more traditional quality approaches, focussing on a preparer- and user-based index that assesses the quantity of disclosure and captures a high level of content, credibility and communication of environmental disclosure (see, Helfaya and Kotb, 2016; Helfaya et al., 2018).

Based on previous literature of corporate disclosure, we have classified the different approaches of measuring the quality of disclosure into two groups: a) Uni-dimensional Measures, and b) Multi-dimensional Measures. These two groups of measures are explained in turn.

\section{First- Uni-dimensional Measures: Simple Measures}

The uni-dimensional measures focus on the quantity of environmental disclosure and the scope (width) of environmental items disclosed.

\section{Quantity Measures}

Quantity measure refers to the amount of information disclosed by companies, taking into account the number of words, sentences or units pages with environmental information. So, every word, sentence or proportion of page with environmental information is considered. It is a simple measure in which quantity can be captured by:

1. Relative Quantity (RQN): the percentage of environmental information within the CSR report (e.g., total number of pages of environmental information/ total number of pages of CSR report).

2. Standardised Quantity Index (SQNI): it captures and standardises the absolute quantity of environmental information (pages) relative to the sample. It is calculated as follows: $\mathrm{SQNI}_{\mathrm{i}}=\left(\mathrm{fl}_{\mathrm{i}}-\min \right) /(\mathrm{Max}-\min )$ 
Where: $\mathbf{f l} \mathbf{i}=$ number of pages with environmental information disclosed by company i, Max $=$ maximum number of pages with environmental information disclosed by a company across the sample, and $\min =$ minimum number of pages with environmental information disclosed by a company across the sample.

\section{Scope Measure (SCI): Un-weighted Index}

Regarding the width of environmental information disclosed, an SCI is used, which is very similar to a great number of the indices employed in the previous literature (Beattie et al., 2004; Guthrie et al., 2008). Given a list of items, the value of the index for a particular company is the result of dividing the number of environmental information items disclosed by that company by the total number of environmental information disclosure items that might be disclosed according to the list. The index is an un-weighted index, so the punctuation of each item is 0 point if there is no environmental information of that item/theme, or 1 point if the information provided, whether that information be narrative, physical, or financial. SCI score is calculated as follows:

$\mathrm{SCI}_{\mathrm{i}}=$ No. items disclosed by company ${ }_{\mathrm{i}} /$ Total possible no. items should be disclosed

\section{Second- Multi-dimensional Measures: Compound Measure}

The multi-dimensional measures are computed in several steps to assess the volume, richness, credibility and/or presentation of the environmental information content (e.g., AlTuwaijri et al., 2004; Helfaya et al., 2018; Michelon et al., 2015; van Staden and Hooks, 2007). In doing so, four compound measures: TQLI, ACHI, SHI, and MQM have been developed and used in previous studies. All of them are delineated below.

\section{Richness Model (TQLI): Width and Depth of Environmental Disclosure}

Regarding the richness of environmental information disclosure, a total quality index (TQLI) is adapted and designed according to Beretta and Bozzolan (2008) and Urquiza et al. (2009) and empirically tested by Michelon et al. (2015). This TQLI is claimed to capture both the quantity and quality of environmental information disclosed by companies. As mentioned above, empirical disclosure studies do not usually differentiate between quantity and quality (Beattie et al., 2004; Helfaya and Kotb, 2016; Michelon et al., 2015) and this measure assesses the 
quality of disclosure measuring both the quantity of environmental information disclosed and the richness of its content as follows:

First: SQNI is captured and standardised the absolute quantity of environmental information (e.g., pages) relative to the sample. It is calculated as follows:

$$
\operatorname{SQNI}_{i}=\left(\mathbf{f l}_{\mathrm{i}}-\min \right) /(\mathbf{M a x}-\min )
$$

Second: A richness index is developed to capture using the quality of environmental disclosure and for this two new dimensions are considered, Width and Depth. Width depends on both the coverage (scope) of important topics (environmental topics disclosed at least once divided by the total number of environmental topics should be disclosed), and on the dispersion of disclosure that measures the concentration of the environmental items disclosed.

So, Coverage and Dispersion are calculated in the following way:

COVERAGE $=$ the Percentage of Environmental Topics (Sub-items) disclosed by the company out of the Total Number of Topics disclosed within the index. It ranges from 0 to 1 and assumes its maximum value when a company makes disclosure over each of the topics within the disclosure index (Beretta and Bozzolan, 2008; Michelon et al., 2015; Urquiza et al., 2009).

DISPERSION = measures the concentration of the items disclosed, where: $\mathrm{Pij}=$ the amount of information disclosed in each topic/item $\mathrm{j}$ (e.g., number of pages) divided by total disclosures of company i (total number of pages with environmental disclosure), while st $=$ is the number of topics (Urquiza et al., 2009).

$$
\begin{aligned}
C O V_{i} & =\frac{1}{s t} \sum_{j=1}^{s t} I N F_{i t} \\
D I S_{i} & =\frac{-\sum_{j=1}^{s t} p_{i j} \ln p_{i j}}{\ln s t}
\end{aligned}
$$


The value of Width dimension (WID) is obtained as the arithmetic mean of the Coverage and Dispersion dimensions. It is calculated as follows:

$$
W H D_{i}=\frac{1}{2}\left(C O V_{i}+D_{I S}\right)
$$

Both coverage and dispersion are related to the richness of the information disclosed by a company. It is argued that the fact of disclosing information about a higher number of important topics/themes is correlated with the richness of information disclosed. Further, the quality of the information will be greater when the quantity information disseminated about every topic is high instead of disclosing only a few information units about certain topics.

Depth (DEP), on the other hand, depends on the type of measures used to disclose the environmental information. These measures range from no disclosure (score $=0$; minimum score) to general narrative disclosure (score $=1$ score) to benchmarking disclosure (score $=$ 4; maximum score) to reflect the usefulness of disclosed information. So, DEP score is calculated for each company $=$ the sum of total items disclosed $*$ their quality scores $(0,1,2$, 3 or 4 ). And then divided by the maximum quality score $=$ No. of disclosure index items/themes $* 4$

Richness: the richness score $(\mathrm{RCN})$ is obtained as a result of averaging the Width and Depth scores. As a result, this index is composed of several dimensions that are expected to be related to the quality of information disclosed. The Richness index for company $i$ is calculated as follows:

$$
R C N_{i}=\frac{1}{2}\left(W I D_{i}+D E P_{i}\right)
$$

TQLI: finally, the TQLI ${ }_{i}$ for company ${ }_{i}$ will be obtained by taking the average of the relative quantity index and the richness index. Simple averages are used since the authors claim there is neither evidence nor theoretical motivation to weight the indices (Beretta and Bozzolan, 2008; Urquiza et al., 2009). The value of the TQLI ranges between 0 and 1. TQLI for company i is calculated as follows: 


\section{$\operatorname{TQLI}_{i}=0.5\left(\operatorname{RQNI}_{i}+\mathrm{RCN}_{i}\right)$}

\section{Al-Tuwaijri, Christensen, and Hughes (2004) Index (ACHI)}

Al-Tuwaijri et al. (2004) developed their quality index (ACHI) based on previous literature, combining the occurrence of the environmental items and the measures used to disclose it. Regarding the occurrence of environmental information, they score the environmental disclosure of each identified disclosure topic or item using a "yes/no", or (1/0). Then, AlTuwaijri et al. (2004) assigned weights to the disclosure items based on the different measures used. For example, quantitative disclosures are awarded score of +3 ; detailed nonquantitative disclosure a score of +2 , general qualitative disclosure a score of +1 ; finally, a company that does not disclose information for given environmental items receive a score 0 . The total quality score (minimum $=0$, maximum of $\mathrm{xx}$ disclosed items $* 3=\mathrm{xx}$ ) is then scaled by the occurrence score $($ minimum $=0$, maximum $=x x$ ). Thus, the environmental disclosure (ACHI) scores range from 0 to +3 (e.g., a company with no environmental disclosure receives minimum score 0 , while company discloses $\mathrm{xx}$ items using quantitative measure receives maximum score of $(\mathrm{xx} * 3 / \mathrm{xx})=3$.

\section{$\mathrm{ACHI}_{\mathrm{i}}=$ Total Quality Score $\mathrm{i} /$ Occurrence Score}

6. van Staden and Hooks (2007) Index (SHI)

van Staden and Hooks (2007) developed an index (SHI) to assess the quality of the disclosures, this SHI is based on a 5-point scale as follows:
a. Score $0=$ no disclosure to this item,
b. Score $1=$ general narrative disclosure to this item,
c. Score $2=$ detailed narrative disclosure to this item,
d. Score 3 = quantitative disclosure to this item, and
e. Score $4=$ benchmarking disclosure to this item.

Thus, the total quality score (SHI) for each company is the sum of total items disclosed * their quality scores $(0,1,2,3$ or 4$)$. This is hen divided by the maximum SHI for $\mathrm{x}$ Items * 4 $=\mathrm{xx}$.

$$
\mathrm{SHI}_{\mathrm{i}}=\mathrm{SHI}_{\mathrm{i}} / \mathrm{xx}
$$




\section{Multi-dimensional Quality Model (MQM)}

This model developed by Helfaya et al. (2018) is based on the findings of a questionnaire ascertaining the quality perceptions of 86 preparers and 177 users of corporate reporting. The analysis of these 263 responses identifies a seven dimensional preparer- and user-based view of assessing reporting quality. This is therefore a less subjective preparer-user's model than one based solely on author perceptions and it indicates that the relative importance to be applied to each of the quality's dimensions for the weighted quality model should be:

Content of environmental information (56\%): 1) Quantity (10\%); 2) Themes (14\%); 3) Measures of disclosure (16\%), and 4) Types of information (16\%).

Credibility of environmental information (31\%): 1) Adopting external reporting guidelines $(16 \%)$, and 2) Inclusion of third-party assurance (15\%).

Communication of environmental information (13\%): using visual tools such as: 1) Tables (4.60\%); Graphs (4.40\%), and Images (4\%).

Hence, this MQM includes 3 overall quality dimensions; quality of content, credibility, and communication (3Cs):

$$
\mathrm{MQM}_{\mathrm{i}}=\mathrm{f}\left(\text { Content }_{\mathrm{i}}, \text { Credibility }_{\mathrm{i}} \text {, and Communication }{ }_{\mathrm{i}}\right)
$$

The varying dimensions covered by these diverse metrics is summarised in the simple Figure 1below. As you will have noted in the discussion above, the calculated inclusion of a dimension may well differ between the metrics, so this figure shows matching areas of interest rather than areas of complete similarity.

Figure 1: Dimensions of Measuring Environmental Sustainability Reporting Quality

\begin{tabular}{|c|c|c|c|c|c|c|}
\hline & Quantity & $\begin{array}{c}\text { Width } \\
\text { (Themes) }\end{array}$ & $\begin{array}{c}\text { Depth } \\
\text { (Measures) }\end{array}$ & $\begin{array}{c}\text { Type of } \\
\text { Information }\end{array}$ & Credibility & Communication \\
\hline \multicolumn{7}{|l|}{ RQN } \\
\hline \multicolumn{7}{|l|}{ SQNI } \\
\hline \multicolumn{7}{|l|}{ SCI } \\
\hline \multicolumn{7}{|l|}{ TQLI } \\
\hline \multicolumn{7}{|l|}{ ACHI } \\
\hline \multicolumn{7}{|l|}{ SHI } \\
\hline MQM & & & & & & \\
\hline
\end{tabular}


To conclude, it is apparent that most studies employ quantity of disclosure or un-weighted disclosure indices based on the level of coverage of certain themes or topics. Despite the wide usage of these measures, there is no empirical evidence supporting the association between either the quantity or coverage and the quality (richness) of information reported by companies. Moreover, such studies lack the benefit of appropriately weighting different types of disclosure (Beattie et al., 2004). Thus, some care is required when using these measures/indices as a measure of disclosure, as a higher quantity or number of disclosure themes is not necessarily a sign of higher information quality. Besides, whilst the design of some of these measures is similar; there is no statistical support for the results generated by these alternative measures being comparable. We conclude that these results might be significantly different despite using similar measures, or building blocks in their design, and subsequently not comparable. The objective of this study, therefore, is to compare the above seven disclosure measures and to investigate how the use of diverse disclosure measures influences the results obtained from a case study of FTSE100 index companies. This leads to the following research question:

\section{Does designing environmental disclosure quality measures make a difference?}

\section{Research Methodology}

\section{Sample}

From a legitimization/moral perspective, companies may symbolically comply with regulative institutional pressures, such as environmental policies and regulations, by adopting corporate sustainability strategies that can help them to gain (extend), maintain and repair (defend) organizational legitimacy (e.g., Bowen, 1953; Campbell et al., 2003; Haque and Ntim, 2018; Garriga and Mele, 2004; Looser and Wehrmeyer, 2015). Additionally, companies may engage in environmental sustainability practices- for more straightforward reasons- in order to protect shareholders' interests, enhance sustainable financial performance or to meet the social expectations of a wide range of stakeholders (see, Bowen, 1953; Brammer and Pavelin, 2008; D’Amico et al., 2016; Friedman, 1962; Garriga and Mele, 2004; Looser and Wehrmeyer, 2015). Consequently, big companies such as FTSE100 companies use environmental sustainability disclosure as a mechanism with the intent to seek legitimacy and social acceptance (legitimation) and to gain positive public image and goodwill (Campbell et al., 2003; D’Amico et al., 2016; Friedman, 1962; Garriga and Mele, 2004; Looser and Wehrmeyer, 2015). 
Noticeably, the UK has experienced high levels of environmental reporting practices (Haque and Ntim, 2018; Jizi, 2017; KPMG, 2017; Michelon et al., 2015). Additionally, the UK FTSE 100 is one of the world's best-known stock exchange indices and a bellwether for the UK capital market. This study, therefore, covers companies listed on the UK FTSE100 for the fiscal year 2010-11 and which issued standalone CRRs during the period of conducting this research. Given that companies from more environmentally polluting industries have been found to disclose more environmental information (Campbell et al., 2003; Robertson \& Samy, 2015; Jizi, 2017; Kalu et al., 2016), it is useful to classify the sampled companies/industries according to their possible environmental impact on environment. Based on prior environmental disclosure literature (e.g., Toms, 2002; Al-Tuwaijri, et al., 2004; Clarkson, et al., 2008; Martinez-Ferrero, et al., 2016; van Staden \& Hooks, 2007;), this study classifies the 74 FTSE100 companies into three groups based on their levels of environmental sensitivity: high environmental sensitivity companies (HES = 30), medium environmental sensitivity companies (MES $=25$ ), and low environmental sensitivity companies (LES = 19). Lastly, companies not issuing a standalone SR have been excluded from the sample, resulting in the final sample consisting of 74 companies within 28 industrial sectors, as seen below in Table 1 . 
Table 1: Sample distribution

Panel (A) Sample selection

UK FTSE 100 companies

100

Less:

Companies did not publish stand-alone CSR reports

Total final sample

(16)

Panel (B) Industry composition

1. High Environmental Sensitivity Industries:

Oil \& Gas $5(7)$

Mining 7 (9)

Aerospace \& Defence 2 (3)

House Hold Goods \& Home 1 (1)

Oil Equipment \& Services 1 (1)

Chemicals 1 (1)

Food Producers 2 (3)

Pharmaceuticals \& Biotechnology 2 (3)

Beverage $2(3)$

Tobacco $2(3)$

Utilities $4(5)$

General Industry 1 (1)

2. Medium Environmental Sensitivity Industries:

\begin{tabular}{ll}
\hline Fixed Line Communication & $1(1)$ \\
Mobile Communication & $1(1)$ \\
Health Care Equipment \& Services & $1(3)$ \\
Food \& Drug Retailers & $3(4)$ \\
General Retailers & $4(5)$ \\
Support Services & $4(5)$ \\
Travel \& Leisure & $6(8)$ \\
Media & $4(5)$ \\
Technology Hardware \& Equipment & $1(1)$ \\
\hline 3. Low Environmental Sensitivity Industries: & \\
\hline Financials (e.g., Banks, Life \& Non-life Insurance, Investment & $18(26)$ \\
Trust, Financial Services, \& Equity Investment an Instruments) & \\
Software \& Computer Services & $1(1)$ \\
\hline Total & $\mathbf{7 4 ( 1 0 0 )}$ \\
\hline
\end{tabular}




\section{Data Collection}

We choose content analysis, a methodology widely adopted in CSR disclosure literature (e.g., Beck et al., 2010; Campbell et al., 2003; Kalu et al., 2016; Michelon et al., 2015; Meng et al., 2014; Patten and Zhao, 2014), to assess the quality of FTSE100 environmental disclosure using the discussed seven quality measures. Following Krippendorff (2004), we organise our data collection into four phases. First, we define the recording unit as a proportion of page to measure the quantity of environmental disclosure devoted to environmental topics/themes. This recording unit covers the limitations of other recording units such as words, sentences and lines and considers both narrative and non-narrative disclosure such as graphs, tables and pictures (Milne and Adler, 1999; Helfaya et al., 2018; Unerman, 2000). Second, we set a coding procedure to capture the disclosure of environmental information. In this procedure, the proportion of pages of analysed environmental sections in stand-alone CRR is counted against the total pages of CRR. For the 32 environmental items, each item is assigned a score of 0 if it is not disclosed and a score of 1 if it is disclosed in the CRR.

Third, an environmental disclosure checklist was developed based on the mainstream CSR literature (e.g., Al-Tuwaijri et al., 2004; Campbell et al., 2003; Cho et al., 2010; Gray et al., 1995; van Staden and Hooks, 2007) and the GRI Standards- G3. This checklist contains six environmental themes: environmental policy; energy and raw materials used (Inputs); environmental-product and process related data (Outputs); environmental-financial data; climate change and sustainability, and environmental others. These are used to represent the six major (mutually exclusive) themes of environmental disclosure. Further, 32 sub-themes are then identified which fell within these main themes. Gray et al. (1995) claim that these sub-themes would be needed in order to allow for the distinction between the main themes and their sub-themes. ${ }^{2}$ Fourth, for the quality of environmental content and its characteristics (qualitative, quantitative, financial, benchmarking, credibility, and presentation), we followed the structure of the compound measures. Two authors first conducted a pilot test of the coding activities to an initial sample of 20 standalone CRRs not only to inform the development of the indexing process, but also as an exercise for the coding activity (Milne and Alder, 1999). Based on the evidence collected in the pilot study, two authors discussed and defined a list of identification and classification rules to supplement the environmental disclosure structure. To avoid inter-coder reliability problems, the first author conducted all

\footnotetext{
${ }^{2}$ This environmental disclosure checklist is available upon request from the authors.
} 
the coding and scoring activities (Krippendorff, 2004; Michelon et al., 2015). Cronbach's Alpha test was conducted to assess the internal consistency reliability of the overall environmental disclosure quality scores produced by the seven measures $(84 \%$, which is above the appropriate minimum acceptable level of 70\%) (Cavana et al., 2001; Kalu et al., 2016). With this four-phase process in mind, it was concluded that the environmental disclosure scores produced by the seven measures are reliable. Table 2 provides details of the seven quality measures used in this study.

Table 2: The Seven Quality Measures

\begin{tabular}{ll}
\hline Quality Measure & Explanation and Computation Formula \\
\hline 1. Relative Quantity & $\begin{array}{l}\text { Relative quantity (\% environmental disclosure of whole CSR } \\
\text { report) }\end{array}$ \\
\hline 2. Standardised & $\begin{array}{l}\text { Standardised quantity (\% disclosure compared to minimum and } \\
\text { Quantity Index }\end{array}$ \\
maximum of sample)
\end{tabular}
(SQNI)

$$
\text { SQNI }=\text { SQNI }_{i}=\left(\mathbf{f l}_{\mathbf{i}}-\min \right) /(\text { Max }- \text { min })
$$

3. Scope Index (SCI) Scope index (un-weighted themes): the number of environmental themes disclosed (\% disclosed themes to the maximum possible number of themes in the disclosure checklist

$$
\operatorname{SCI}_{i}=\frac{1}{n i} \sum_{\mathbf{j}=1}^{n i} \mathbf{d}
$$

4. Total Quality Index Total quality index (quantity, themes, and richness of disclosure)

\begin{tabular}{|c|c|}
\hline & $\operatorname{TQLI}_{\mathbf{i}}=\frac{1}{2}\left(\mathrm{SQNI}_{\mathrm{i}}+\mathrm{RICH}_{\mathrm{i}}\right)$ \\
\hline \multirow[t]{2}{*}{$\begin{array}{l}\text { 5. Weighted Quality } \\
\text { Index (ACHI) }\end{array}$} & $\begin{array}{l}\text { Al-Tuwaijri et al's (2004) weighted index (richness of themes } \\
\text { disclosed) }\end{array}$ \\
\hline & ACHI $_{i}=$ Total Quality Score $_{\mathrm{i}} /$ Occurrence Score \\
\hline \multirow[t]{2}{*}{$\begin{array}{l}\text { 6. Weight Quality } \\
\text { Index (SHI) }\end{array}$} & $\begin{array}{l}\text { van Staden and Hooks' (2007) weighted index (themes weighed } \\
\text { by richness of disclosure) }\end{array}$ \\
\hline & $\operatorname{SHI}_{\mathrm{i}}=\frac{1}{\mathrm{ni}} \sum_{\mathbf{j}=\mathbf{1}}^{\mathrm{ni}} \mathbf{w} \mathbf{j} \mathbf{d} \mathbf{j}$ \\
\hline \multirow[t]{2}{*}{$\begin{array}{l}\text { 7. Multidimensional } \\
\text { Quality Model } \\
\text { (MQM) }\end{array}$} & $\begin{array}{l}\text { Multi-dimensional quality model: a seven dimensional model } \\
\text { (quantity, themes, measures, information types, assurance, } \\
\text { standard adoption, visual tools) weighted by questionnaire } \\
\text { responses }\end{array}$ \\
\hline & MQM $_{i}=\sum$ Content $_{i}+$ Credibility $_{i}+$ Communication $_{i}$ \\
\hline
\end{tabular}
(TQLI) 


\section{Results and analysis}

\section{An Overview of the Alternative Reporting Quality Measures}

Table 3 summarises the descriptive statistics on the values of the alternative measures. In particular, there is very little difference between the results using RQN and SQNI (with a mean score of 0.32 and 0.25 , respectively). This result indicates that it is better for evaluating the quality of environmental disclosure to link the quantity of this disclosure to the total quantity of the whole CRR rather than to the minimum and maximum quantity of environmental disclosure across the sample. This table reports that, on average, two measures (SCI and SHI) provide approximately the same number of references related to the quality of environmental information (with a mean score of 0.71 and 0.70 , respectively). Therefore, it can be argued that there is no significant difference between un-weighted (SCI) and weighted indices (SHI) in assessing the disclosure quality. While both ACHI and SHI can be considered weighted indices, both generate significant different means, medians, and Std. Dev, as seen in Table 3. This due mainly to the formulas used in computing these measures.

Regarding more complicated measures, MQM generates higher quality scores than those of TQLI (with mean of 53.81 and 0.49 , respectively). This is due to two reasons: a) the formula of each measure, and b) the dimensions covered by each measure. Therefore, it is not surprising that both measures yield dissimilar results. Additionally, while ACHI, SHI, and TQLI cover the richness of information content, MQM covers not only richness of content, but also its credibility and presentation. As a result, it is contended that MQM is the best among the seven alternative measures. The values of Std. Dev, skewness, and kurtosis for most measures show that these measures are not normally distributed, and this conclusion is tested statistically by the Kolmogorov-Smirnov test (K-S), as noted in Table 3 below. 
Table 3: Descriptive Statistics for the Alternative Quality Measures

\begin{tabular}{|c|c|c|c|c|c|c|c|c|c|c|c|}
\hline \multirow{2}{*}{ Quality Measure } & \multirow[b]{2}{*}{$\mathbf{N}$} & \multirow[b]{2}{*}{ Mean } & \multirow[b]{2}{*}{ Median } & \multirow[b]{2}{*}{ Std. Dev } & \multirow[b]{2}{*}{ Min } & \multirow[b]{2}{*}{$\operatorname{Max}$} & \multirow[b]{2}{*}{ Skewness } & \multirow[b]{2}{*}{ Kurtosis } & \multicolumn{3}{|c|}{$\begin{array}{c}\text { Test of Normality } \\
\text { Kolmogorov-Smirnov }{ }^{1}\end{array}$} \\
\hline & & & & & & & & & Statistic & df & Sig. \\
\hline \multicolumn{12}{|l|}{ Simple: } \\
\hline RQN & 74 & 0.32 & 0.28 & 0.15 & 0.07 & 1.00 & 1.73 & 4.93 & 0.150 & 74 & 0.000 \\
\hline SQNI & 74 & 0.25 & 0.17 & 0.22 & 0.00 & 1.00 & 1.60 & 2.58 & 0.160 & 74 & 0.000 \\
\hline SCI & 74 & 0.71 & 0.72 & 0.12 & 0.44 & 0.94 & -0.22 & -0.43 & 0.110 & 74 & 0.028 \\
\hline \multicolumn{12}{|l|}{ Compound: } \\
\hline TQLI & 74 & 0.49 & 0.46 & 0.14 & 0.27 & 0.90 & 0.96 & 0.95 & 0.100 & 74 & 0.065 \\
\hline ACHI & 74 & 2.80 & 2.83 & 0.16 & 2.27 & 3.00 & -0.96 & 0.73 & 0.116 & 74 & 0.015 \\
\hline SHI & 74 & 0.70 & 0.71 & 0.12 & 0.44 & 0.92 & 0.27 & -0.45 & 0.087 & 74 & $0.200^{\mathrm{a}}$ \\
\hline MQM & 74 & 53.81 & 58.35 & 17.44 & 20.64 & 83.99 & -0.29 & -1.29 & 0.149 & 74 & 0.000 \\
\hline
\end{tabular}


Regarding the most complicated measures, TQLI and MQM, Table 4 below records the descriptive statistical results of the detailed TQLI's and MQM's dimensions. Both measures cover similar aspects of reporting quality: quantity, scope, type, the richness of information, but MQM additionally covers the credibility of this information and how it is presented to users. We also report MQM split into the three component sub-elements mentioned above. With regard to measuring disclosure quantity, both SQNI-TQLI and RQN-MQM are used, but their designs mean that there is a significant difference between the headline reported statistics (with a mean of 0.25 and 3.17, respectively). This is also true of COV and THMMQM, which are designed to measure the coverage of different environmental topics, where means are 0.71 and 10.35, respectively. This highlights the importance of the detail in calculation with COV using the percentage of environmental topics covered, while THMMQM uses the percentage of disclosing each environmental topic and sub-topics covered* the weighted quality point to this topic/theme. This same lack of immediate comparability can be seen with DEP, MES- MQM and INFTYP- MQM measuring the type of information disclosed (i.e., qualitative, quantitative, looking-forward information, bad news, etc.), with means being $0.70,7.57$, and 8.80 , respectively.

Although both TQLI and MQM are compound measures that cover many characteristics of the quality of information content, it is contended that the full MQM (mean of 53.81) is better than TQLI (mean of 0.49) for assessing reporting quality as it is preparer-user based and also cover a further two aspects of reporting quality; reliability and presentation of content. It is noted that standard deviations are large for some dimensions relative to their means, and hence the metrics are recording significant differences in perceived quality across the sample. Significant values of both skewness and kurtosis, as seen in Table 4, also confirm the distributional complexity of this dispersion of data. 
Table 4: Descriptive Statistics for the TQLI and MQM Dimensions used in the Study

\begin{tabular}{|c|c|c|c|c|c|c|c|c|c|c|c|}
\hline \multirow[t]{2}{*}{ Quality Measure } & \multirow[b]{2}{*}{$\mathbf{N}$} & \multirow[b]{2}{*}{ Mean } & \multirow[b]{2}{*}{ Median } & \multirow{2}{*}{$\begin{array}{l}\text { Std. } \\
\text { Dev }\end{array}$} & \multirow[b]{2}{*}{ Min } & \multirow[b]{2}{*}{ Max } & \multirow[b]{2}{*}{ Skewness } & \multirow[b]{2}{*}{ Kurtosis } & \multicolumn{3}{|c|}{$\begin{array}{c}\text { Normality Test } \\
\text { Kolmogorov-Sminrov }\end{array}$} \\
\hline & & & & & & & & & Statistic & df & Sig. \\
\hline SQNI- TQLI & 74 & 0.25 & 0.17 & 0.22 & 0.00 & 1.00 & 1.60 & 2.58 & 0.158 & 74 & 0.000 \\
\hline COV-TQLI & 74 & 0.71 & 0.72 & 0.12 & 0.44 & 0.94 & -0.22 & -0.43 & 0.110 & 74 & 0.028 \\
\hline DIS- TQLI & 74 & 0.80 & 0.81 & 0.06 & 0.65 & 0.94 & -0.54 & 0.19 & 0.141 & 74 & 0.001 \\
\hline WID- TQLI & 74 & 0.76 & 0.76 & 0.08 & 0.58 & 0.90 & -0.22 & -0.59 & 0.064 & 74 & $0.200^{\mathrm{a}}$ \\
\hline DEP- TQLI & 74 & 0.70 & 0.71 & 0.12 & 0.44 & 0.92 & -0.27 & -0.45 & 0.087 & 74 & $0.200^{\mathrm{a}}$ \\
\hline TRICH- TQLI & 74 & 0.73 & 0.74 & 0.10 & 0.53 & 0.91 & -0.25 & -0.53 & 0.550 & 74 & $0.200^{\mathrm{a}}$ \\
\hline TQLI & 74 & 0.49 & 0.46 & 0.14 & 0.27 & 0.90 & 0.96 & 0.94 & 0.100 & 74 & 0.065 \\
\hline RQN-MQM & 74 & 3.17 & 2.80 & 1.54 & 0.73 & 10.00 & 1.73 & 4.96 & 0.152 & 74 & 0.000 \\
\hline THM- MQM & 74 & 10.35 & 10.51 & 1.61 & 5.91 & 13.33 & -0.46 & 0.01 & 0.085 & 74 & $0.200^{\mathrm{a}}$ \\
\hline MES- MQM & 74 & 7.57 & 7.49 & 2.00 & 3.05 & 11.56 & -0.08 & -0.45 & 0.063 & 74 & $0.200^{\mathrm{a}}$ \\
\hline INFTYP- MQM & 74 & 8.80 & 9.03 & 1.73 & 4.85 & 12.44 & -0.22 & -0.39 & 0.062 & 74 & $0.200^{\mathrm{a}}$ \\
\hline TCONT- MQM & 74 & 29.89 & 30.72 & 6.00 & 16.45 & 43.01 & -0.29 & -0.43 & 0.073 & 74 & $0.200^{\mathrm{a}}$ \\
\hline CRED- MQM & 74 & 19.05 & 31.00 & 13.47 & 0.00 & 31.00 & -0.47 & -1.53 & 0.326 & 74 & 0.000 \\
\hline COMM- MQM & 74 & 4.86 & 4.49 & 2.62 & 1.15 & 13.00 & -0.63 & -0.02 & 0.091 & 74 & $0.200^{\mathrm{a}}$ \\
\hline MQM & 74 & 53.81 & 58.35 & 17.44 & 20.64 & 83.99 & -0.29 & -1.29 & 0.149 & 74 & 0.000 \\
\hline
\end{tabular}

SQNI: Standardised Quantity Index; COV: Coverage; DIS: Dispersion; WID: Width; DEP: Depth; TRICH: Total Richness; TQLI: Total Quality Index; RQN-MQM: Relative Quantity-MQM; THM-MQM: Themes-MQM: MES-MQM: Measures-MQM; INFTYP-MQM: Information Type-MQM; TCON-MQM: Total Content; CRED-MQM: Credibility-MQM; COMM-MQM: Communication- MQM. 


\section{Correlations between Alternative Reporting Quality Measures}

Table 5 presents correlation coefficients between the seven quality measures. The values of these seven quality measures are expected to be correlated, since the measures share the same overall purpose, to measure the quality of environmental disclosure. Since the seven measures do not follow a normal distribution, except TQLI and SHI measures, as indicated by Kolmogorov-Smirnov Test (see, Table 3 above), the Spearman rank test is used. Further, as the median does not differ greatly from the mean, it can be claimed there is no presence of outliers at one end of the distribution. Whilst it is important to mention that the values of all measures have significant correlations with each other as had been expected, some measures have higher correlations with other metrics than others. It is worth noting that the two highest correlations are between the SCI and SHI measures (0.992 at the 0.000 level), and between the SQNI and TQLI measures (0.956 at the 0.000 level). Furthermore, RQN is not highly correlated with any of the other measures. However, the other measure of quantity, SQNI, is highly correlated with the other measures compared to RQN. This result suggests that quantity can be important in assessing quality. SQNI's formula for measuring quantity appears to lead to greater congruence with other quality measure than RQN.

The correlation matrix between the results of quality scores using the compound measures TQLI and SHI results in the highest level of correlation. The Spearman Correlation between these two quality scores is positive and highly significant, being 0.889 . The correlation matrix shows the quality scores produced by MQM and SHI are also it is statistically highly correlated (0.753). Finally, the correlation coefficients of both simple and compound measures are seen to be statistically significant. However, this does not necessarily imply that using different measures will not have a significant impact on the results of the disclosure studies that use this kind of quality measures. Although they may be assessing information attributes that might be related, the use of one measure or another will lead to a different environmental disclosure quality ranking of companies being analysed and as a result, affect the empirical evidence attained. As before, quality is concerned with fitness for purpose, and if the purpose is to discover which company produces the higher quality of environmental reporting, then the ranking of individual companies becomes the issue rather than overall similarity of results. 
Table 5: Correlation Matrix

\begin{tabular}{|c|c|c|c|c|c|c|c|}
\hline Quality Measure & RQN & SQNI & SCI & TQLI & ACHI & SHI & MQM \\
\hline RQN & 1.000 & $\begin{array}{l}0.574^{* *} \\
(0.000)\end{array}$ & $\begin{array}{l}0.485^{\text {** }} \\
(0.000)\end{array}$ & $\begin{array}{l}0.606^{\text {** }} \\
(0.000)\end{array}$ & $\begin{array}{l}0.354^{* *} \\
(0.002)\end{array}$ & $\begin{array}{l}0.511^{* *} \\
(0.000)\end{array}$ & $\begin{array}{l}0.363^{* *} \\
(0.001)\end{array}$ \\
\hline SQNI & & 1.000 & $\begin{array}{l}0.730^{* * *} \\
(0.000)\end{array}$ & $\begin{array}{l}0.956^{* *} \\
(0.000)\end{array}$ & $\begin{array}{l}0.503^{* *} \\
(0.000)\end{array}$ & $\begin{array}{l}0.743^{* *} \\
(0.000)\end{array}$ & $\begin{array}{l}0.607^{* *} \\
(0.000)\end{array}$ \\
\hline SCI & & & 1.000 & $\begin{array}{l}0.877^{* *} \\
(0.000)\end{array}$ & $\begin{array}{l}0.568^{* * *} \\
(0.000)\end{array}$ & $\begin{array}{l}0.992^{* *} \\
(0.000)\end{array}$ & $\begin{array}{l}0.750^{* *} \\
(0.000)\end{array}$ \\
\hline TQLI & & & & 1.000 & $\begin{array}{l}0.546^{* *} \\
(0.000)\end{array}$ & $\begin{array}{l}0.889^{* *} \\
(0.000)\end{array}$ & $\begin{array}{l}0.692^{* * *} \\
(0.000)\end{array}$ \\
\hline ACHI & & & & & 1.000 & $\begin{array}{l}0.564^{* *} \\
(0.000)\end{array}$ & $\begin{array}{l}0.569^{* * *} \\
(0.000)\end{array}$ \\
\hline SHI & & & & & & 1.000 & $\begin{array}{l}0.753^{* * *} \\
(0.000)\end{array}$ \\
\hline MQM & & & & & & & 1.000 \\
\hline
\end{tabular}

**. Correlation is significant at the 0.01 level (2-tailed).

With regard to the most two complicated measures, TQLI and MQM; some interesting conclusions might be drawn from the results presented in Table 6 below, where each metric is broken into its component parts. As expected, the correlation matrix reports significant and relatively high correlations across most dimensions of both TQLI and MQM. For TQLI and its dimensions, as might be expected, the two highest correlations are between coverage (COV) and depth (DEP) dimensions (0.992), and between DEP and total richness (TRICH) (0.987). Whilst the lowest correlations are between dispersion (DIS) and both TQLI and COV (0.282 and 0.355 respectively). However, there is no relationship between SQNI and DIS dimensions. The dimensions that comprise width- i.e. COV and DIS are correlated with the WID index. Those that comprise the richness index - i.e. WID and DEP are also correlated with the TRICH. The COV and DIS dimensions are also correlated, although the correlation is lower but statistically significant $(0.355$ at the 0.002 level). The correlation between SQNI and DIS (0.154) is not statistically significant. It would seem, therefore, that they measure different aspects of information richness. So it might be concluded that quantity index designed as most of the measures in previous CSR literature would not capture all features of information quality. 
Regarding the MQM dimensions, Table 6 reports that the dimensions that compose total content- i.e. relative quantity (RQN), themes (THM), measures (MES), and information type (INFTYP)- are correlated with the total content (TCONT). Correlations are the highest and statistically significant between TCONT and INFTYP (0.946 and 0.944 respectively). Further, those measures that comprise the MQM- i.e. total content (TCONT), Credibility (CRED), and communication (COMM) are also correlated with the MQM, although the correlation between COMM and MQM is relatively low (0.427), it is still statistically significant $(\mathrm{p}<0.01)$. The correlations among THM, MES, and INFTYP are high and statistically significant as expected. Finally, Table 6 also includes correlations between the dimensions of MQM and MQM itself and the RQN. Interestingly, there is no relationship between RQN and CRED dimension (0.012), the value being insignificant, suggesting that they measure different aspects of information quality. Moreover, the correlation between RQN and MQM is relatively low (0.370) - though still significant $(\mathrm{p}<0.01)$. So the range of correlations across the measures varies as expected, the highest correlations are between COV-TQLI and both INFTYP-MQM and THM-MQM (0.969 and 0.951 respectively), and between DEP-TQLI and both THM-MQM and TCONT-MQM (0.947 and 0.945 respectively). Furthermore, TRICH- TQLI is highly correlated with both INFTYP-MQM and TCONT-MQM (0.955 and 0.944 respectively). The lowest correlations are between CRED-MQM and both SQNI-TQLI and TQLI (0.320 and 0.366 respectively). 
Table 6: Correlation between TQLI and MQM Dimensions

\begin{tabular}{|c|c|c|c|c|c|c|c|c|c|c|c|c|c|c|c|}
\hline $\begin{array}{l}\text { Quality } \\
\text { Measure }\end{array}$ & SQNI & $\mathrm{COV}$ & DIS & WID & DEP & TRICH & TQLI & $\begin{array}{l}\text { RQN- } \\
\text { MQM }\end{array}$ & $\begin{array}{l}\text { THM- } \\
\text { MQM }\end{array}$ & $\begin{array}{l}\text { MES- } \\
\text { MQM }\end{array}$ & $\begin{array}{l}\text { INFTYP- } \\
\text { MQM }\end{array}$ & $\begin{array}{r}\text { TCONT- } \\
\text { MQM }\end{array}$ & $\begin{array}{l}\text { CRED- } \\
\text { MQM }\end{array}$ & $\begin{array}{l}\text { COMM- } \\
\text { MQM }\end{array}$ & MQM \\
\hline \multirow[t]{2}{*}{ SQNI- TQLI } & 1.000 & $0.730^{* * *}$ & 0.154 & $0.626^{* *}$ & $0.743^{* *}$ & $0.710^{* *}$ & $0.956^{* *}$ & $0.582^{* *}$ & $0.744^{* *}$ & $0.752^{* *}$ & $0.727^{* *}$ & $0.800 * *$ & $0.320^{* *}$ & $0.403^{* *}$ & $0.607^{* * *}$ \\
\hline & . & $(0.000)$ & $(0.190)$ & $(0.000)$ & $(0.000)$ & $(0.000)$ & $(0.000)$ & $(0.000)$ & $(0.000)$ & $(0.000)$ & $(0.000)$ & $(0.000)$ & $(0.005)$ & $(0.000)$ & $(0.000)$ \\
\hline \multirow[t]{2}{*}{ COV-TQLI } & & 1.000 & $0.355^{* *}$ & $0.929^{* *}$ & $0.992^{* *}$ & $0.985^{* *}$ & $0.877^{* *}$ & $0.493^{* *}$ & $0.951^{\text {** }}$ & $0.879^{* *}$ & $0.969^{* *}$ & $0.942 * *$ & $0.453^{* *}$ & $0.410^{* *}$ & $0.750^{* *}$ \\
\hline & & & $(0.002)$ & $(0.000)$ & $(0.000)$ & $(0.000)$ & $(0.000)$ & $(0.000)$ & $(0.000)$ & $(0.000)$ & $(0.000)$ & $(0.000)$ & $(0.000)$ & $(0.000)$ & $(0.000)$ \\
\hline \multirow{2}{*}{ DIS- TQLI } & & & 1.000 & $0.649^{* * *}$ & $0.359^{* *}$ & $0.480^{* * *}$ & $0.282^{*}$ & 0.170 & $0.405^{* * *}$ & $0.374^{* * *}$ & $0.302^{* *}$ & $0.369 * *$ & 0.042 & 0.128 & 0.201 \\
\hline & & & . & $(0.000)$ & $(0.002)$ & $(0.000)$ & $(0.015)$ & $(0.148)$ & $(0.000)$ & $(0.001)$ & (0.009) & $(0.001)$ & $(0.724)$ & $(0.278)$ & $(0.087)$ \\
\hline WID- TQLI & & & & 1.000 & $0.924^{* *}$ & $0.971^{* *}$ & $0.797^{* *}$ & $0.462^{* *}$ & $0.917^{* *}$ & $0.849^{* *}$ & $0.884^{* *}$ & $0.896 * *$ & $0.355^{* *}$ & $0.385^{* *}$ & $0.666^{* * *}$ \\
\hline \multirow{2}{*}{ DEP- TQLI } & & & & & 1.000 & $0.987^{* *}$ & $0.889^{* *}$ & $0.519^{* * *}$ & $0.947^{* * *}$ & $0.870^{* * *}$ & $0.970^{* *}$ & $0.945^{* *}$ & $0.451^{* *}$ & $0.420^{* * *}$ & $0.753^{* * *}$ \\
\hline & & & & & 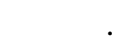 & $(0.000)$ & $(0.000)$ & $(0.000)$ & $(0.000)$ & $(0.000)$ & $(0.000)$ & $(0.000)$ & $(0.000)$ & $(0.000)$ & $(0.000)$ \\
\hline \multirow[t]{2}{*}{ TRICH- TQLI } & & & & & & 1.000 & $0.867^{* *}$ & $0.501^{* *}$ & $0.954^{* *}$ & $0.881^{* *}$ & $0.955^{* *}$ & $0.944 * *$ & $0.418^{* *}$ & $0.400^{* * *}$ & $0.727^{* * *}$ \\
\hline & & & & & & & $(0.000)$ & $(0.000)$ & $(0.000)$ & $(0.000)$ & $(0.000)$ & $(0.000)$ & $(0.000)$ & $(0.000)$ & $(0.000)$ \\
\hline \multirow[t]{2}{*}{ TQLI } & & & & & & & 1.000 & $0.615^{* *}$ & $0.875^{* *}$ & $0.843^{* *}$ & $0.863^{* *}$ & $0.911 * *$ & $0.366^{* *}$ & $0.453^{* *}$ & $0.692^{* * *}$ \\
\hline & & & & & & & . & $(0.000)$ & $(0.000)$ & $(0.000)$ & $(0.000)$ & $(0.000)$ & $(0.001)$ & $(0.000)$ & $(0.000)$ \\
\hline \multirow{2}{*}{ RQN- MQM } & & & & & & & & 1.000 & $0.516^{* *}$ & $0.498^{* *}$ & $0.490^{* * *}$ & $0.652 * *$ & 0.012 & $0.653^{* *}$ & $0.370^{* * *}$ \\
\hline & & & & & & & & . & $(0.000)$ & $(0.000)$ & $(0.000)$ & $(0.000)$ & $(0.917)$ & $(0.000)$ & $(0.001)$ \\
\hline THM- MQM & & & & & & & & & . & $(0.000)$ & $(0.000)$ & $(0.000)$ & $(0.000)$ & $(0.001)$ & $(0.000)$ \\
\hline \multirow[t]{2}{*}{ MES- MQM } & & & & & & & & & & 1.000 & $0.878^{* * *}$ & $0.927 * *$ & $0.435^{* *}$ & $0.461^{* *}$ & $0.747^{* * *}$ \\
\hline & & & & & & & & & & 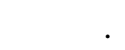 & $(0.000)$ & $(0.000)$ & $(0.000)$ & $(0.000)$ & $(0.000)$ \\
\hline \multirow{2}{*}{ INFTYP- MQM } & & & & & & & & & & & 1.000 & $0.944 * *$ & $0.482^{* *}$ & $0.411^{* *}$ & $0.769^{* * *}$ \\
\hline & & & & & & & & & & & . & $(0.000)$ & $(0.000)$ & $(0.000)$ & $(0.000)$ \\
\hline \multirow[t]{2}{*}{ TCONT- MQM } & & & & & & & & & & & & 1.000 & $0.395 * *$ & $0.523 * *$ & $0.759 * *$ \\
\hline & & & & & & & & & & & & & $(0.000)$ & $(0.000)$ & $(0.000)$ \\
\hline \multirow{2}{*}{ CRED- MQM } & & & & & & & & & & & & & 1.000 & 0.086 & $0.871^{* * *}$ \\
\hline & & & & & & & & & & & & & & $(0.464)$ & $(0.000)$ \\
\hline \multirow[t]{2}{*}{ COMM- MQM } & & & & & & & & & & & & & & 1.000 & $0.427^{* *}$ \\
\hline & & & & & & & & & & & & & & & $(0.000)$ \\
\hline MQM & & & & & & & & & & & & & & & 1.000 \\
\hline
\end{tabular}

*. Correlation is significant at the 0.05 level (2-tailed); **. Correlation is significant at the 0.01 level (2-tailed). 


\section{Deviations of Alternative Quality Measures' Rankings}

It needs to be remembered that a statistically significant relationship means that one would be better predicting one set of rankings from the other rather than by using random selection. Hence, as shown in Table 5 above, a correlation of 0.363 implies one would be $36 \%$ better at predicting MQM ranks by using the RQN rankings than just random selection. However, SHI would be $75 \%$ better at predicting MQM ranks than random selection - clearly a much more meaningful and potentially useful proxy. With a relatively large sample of 74 companies, even relatively low correlations may still be significantly different from random selection, whilst still giving little accurate guidance to a company's rank according to the comparator ranking system. Note, for example, that SQNI, which assesses environmental quantity compared to the sample's range of quantities, is a $61 \%$ improvement over a random selection, whereas RQN, where environmental disclosure quantity is just a percentage of a company's whole CSR report, is only a $36 \%$ improvement.

Next, as presented in Table 7 below companies are ranked according to the values of each quality measure in order to assess the effects of using different quality measures on these rankings. The results show differences when companies are ranked according to the values of the seven alternative quality measures. With regards to companies' rankings, there are more differences between the RQN and SQNI, however, both measure the quantity of disclosure using different criteria. Both agree on the lowest company in the sample- BAE SYSTEMS- achieving some of the lowest scores across most measures, while the highest difference is achieved by GLAXOSMITHKLINE (64). Focusing just on RQN and SQNI, 29 companies are within 10 ranking positions using both metrics. Whilst 45 are more than 10 places apart- 23 being more than 20 places apart. For example, regardless their higher rankings using RQN, BRITISH LAND and RECKITT BENCKISER (6 and 8 respectively), score, 23 and 38 using SQNI, which more closely reflect their rank other measures. With regard to SCI (un-weighted) and SHI (weighted) measures, there are very few differences between the measures. Both agree on 27 companies (36\%), while 67 companies (91\%) are within 5 rank positions of each other. Indeed, the maximum difference in rank is 12 with $\mathbf{J}$ SAINSBURY disclosing relatively more qualitative information.

Looking at ACHI which combines the occurrence and quality of disclosure, 7 companies have scored an impressive 1 , however, the range across of the seven measures for these companies is a relatively low varying 14 for $M \& S$ to a very high for 67 
GLAXOSMITHKLINE. This significant difference is due to the construction of the measure, compared to other measures. For example, the best company by mean rank position- HAMMERSON- achieves the highest scores using SCI, SHI, and MQM, and the second and third highest scores using TQLI and SQNI respectively, yet comes the fourteenth using ACHI. TQLI and MQM have some degree of ranking conformity with two companies MAN GROUP and STANDARD CHARTERED being identically ranked and 20 of the 74 companies $(27 \%)$ being within 5 or fewer ranks of each other, 33 within 10 or less rank positions yet 18 more than 20 places apart, with. SCOTTISH \& SOUTHERN ENERGY being 42 places apart by these measures. This can be explained by the MQM that covers credibility and presentation of content for which SCOTTISH \& SOUTHERN ENERGY scored 0 for credibility and just 5.9 points for presentation (43\%). Therefore, this significant difference in rank between TQLI and MQM is due to the differing dimensions covered by both and due to the formula of calculation.

When all seven measures are compared, most of them agree that the very high level of environmental disclosure quality is found in HAMMERSON's CSR report- from LESI- with all but one metric putting it top or at least in the top four. There also seems to be general consensus that BT and KINGFISHER- from MESI- have a good quality of environmental information. In contrary, all measures appear to concur that BAE SYSTEMS and SHIRE (from HESI) produce the lowest level of environmental reporting quality. According to a range of ranks, few companies (9\%) have a range of ranks of 15 or less, as seen in Table 7. In contrast, large differences appear across the seven measures for 27 companies (36\%) have a range of ranks between 15 and 30, and 40 companies (55\%) have a range of ranks between 30 and 67. However, there is no any discernible pattern in these differences.

Some companies scored a similar relative value for more than one quality measure and therefore they are in the same place of ranking. For instance, JOHNSON MATTHEY comes nineteenth using SQNI, and SCI and a similar, twenty-first using TQLI and SHI. However, this does not influence the general conclusions, as there are important differences; some companies score a high place in the ranking according to one of the quality measures and, at the same time, are in one of the lowest places in the ranking according to some of the other measures. LEGAL \& GENERAL, for example, comes first using ACHI and fifty-first using MQM, whilst BARRICK comes first using SCI, and thirty-seventh using RQN. 
Table 7 also represents the results of rank, mean rank and deviation of the alternative quality measures. The results demonstrate that on average the deviation of the mean rank is 11.92, and the range of mean deviation varies from a minimum of 3.87 to a maximum of 23.98 . The conclusion from this is that from the perspective of individual company ranking there can be a large difference across the alternative quality measures. This can be explained by the fact that disclosure quality scores are based on various dimensions of assessing quality from quantity, to coverage of topics covered, to type and nature of the information disclosed, to adopting reporting standards, to the inclusion of environmental audit, and using presentation tools. Therefore, these differences in the design of the disclosure quality measures are likely to impact on the results obtained in the previous disclosure literature studies, with perceptions of quality perhaps influenced more by the lens of methodology than broader reality. To conclude, comparisons among different disclosure quality measures have been performed by using descriptive procedures, and some evidence is found about the impact of using any one measure rather than an alternative to assess the environmental sustainability disclosure quality of 74 constituent members of the FTSE100 index. Thus, from the results above, it can be concluded that it does make a difference in disclosure research when deciding to use one particular quality measure over another. 
Table 7: Deviations of Alternative Quality Measures' Rankings

\begin{tabular}{|c|c|c|c|c|c|c|c|c|c|c|}
\hline COMPANY NAME & RQN & SQNI & SCI & TQLI & ACHI & SHI & MQM & MEAN & 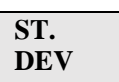 & RANGE \\
\hline 1. BT & 11 & 1 & 9 & 1 & 8 & 10 & 2 & 6.00 & 4.47 & 10 \\
\hline 2.WHITBREAD & 10 & 9 & 12 & 9 & 18 & 15 & 7 & 11.43 & 3.87 & 11 \\
\hline 3. ARM & 70 & 68 & 73 & 71 & 70 & 73 & 61 & 69.43 & 4.12 & 12 \\
\hline 4. HAMMERSON & 4 & 3 & 1 & 2 & 14 & 1 & 1 & 3.71 & 4.68 & 13 \\
\hline 5. $M \& S$ & 7 & 14 & 12 & 15 & 1 & 15 & 8 & 10.29 & 5.22 & 14 \\
\hline 6. BAE SYSTEMS & 72 & 72 & 71 & 74 & 74 & 71 & 59 & 70.43 & 5.19 & 15 \\
\hline 7. SHIRE & 72 & 71 & 59 & 67 & 73 & 59 & 74 & 67.86 & 6.44 & 15 \\
\hline 8. SAB MILLER & 25 & 36 & 31 & 38 & 21 & 35 & 24 & 30.00 & 6.68 & 17 \\
\hline 9. PEARSON & 55 & 58 & 62 & 66 & 64 & 68 & 72 & 63.57 & 5.83 & 17 \\
\hline 10. CENTRICA & 27 & 12 & 9 & 11 & 14 & 9 & 13 & 13.57 & 6.21 & 18 \\
\hline 11. G4S & 66 & 60 & 53 & 60 & 66 & 52 & 70 & 61.00 & 6.81 & 18 \\
\hline 12. KINGFISHER & 3 & 2 & 19 & 4 & 8 & 21 & 3 & 8.57 & 8.06 & 19 \\
\hline 13. VODAFONE & 20 & 16 & 19 & 16 & 1 & 18 & 12 & 14.57 & 6.53 & 19 \\
\hline 14. INVENSYS & 19 & 40 & 26 & 35 & 36 & 26 & 20 & 28.86 & 8.21 & 21 \\
\hline 15. BRITISH AMERICAN & 44 & 33 & 43 & 41 & 53 & 46 & 32 & 41.71 & 7.34 & 21 \\
\hline 16. TESCO & 59 & 37 & 48 & 49 & 49 & 58 & 45 & 49.29 & 7.54 & 22 \\
\hline 17. 3i GROUP & 46 & 69 & 62 & 68 & 59 & 62 & 46 & 58.86 & 9.46 & 23 \\
\hline 18. MAN GROUP & 69 & 46 & 59 & 53 & 57 & 59 & 53 & 56.57 & 7.11 & 23 \\
\hline 19. BP & 20 & 34 & 43 & 44 & 38 & 42 & 30 & 35.86 & 8.65 & 24 \\
\hline 20. BSKYB & 28 & 7 & 12 & 8 & 31 & 12 & 10 & 15.43 & 9.83 & 24 \\
\hline 21. RSA & 30 & 25 & 31 & 26 & 45 & 31 & 21 & 29.86 & 7.63 & 24 \\
\hline 22. XSTRATA & 28 & 8 & 3 & 6 & 14 & 3 & 4 & 9.43 & 9.05 & 25 \\
\hline 23. NEXT & 33 & 35 & 26 & 37 & 51 & 29 & 33 & 34.86 & 8.01 & 25 \\
\hline 24. MORRISONS & 36 & 59 & 43 & 54 & 61 & 42 & 60 & 50.71 & 10.19 & 25 \\
\hline 25. STANDARD CHATERED & 46 & 72 & 71 & 73 & 71 & 72 & 73 & 68.29 & 9.86 & 27 \\
\hline 26. CAIRN & 30 & 6 & 19 & 7 & 34 & 18 & 28 & 20.29 & 11.03 & 28 \\
\hline 27. BARCLAYS & 46 & 54 & 62 & 59 & 59 & 62 & 34 & 53.71 & 10.34 & 28 \\
\hline 28. SHELL & 14 & 32 & 3 & 23 & 14 & 5 & 5 & 13.71 & 10.70 & 29 \\
\hline 29. LAND SECURITIES & 37 & 26 & 12 & 22 & 18 & 12 & 41 & 24.00 & 11.47 & 29 \\
\hline 30. TULLOW & 62 & 43 & 68 & 62 & 71 & 69 & 42 & 59.57 & 12.15 & 29 \\
\hline 31. SMITHS & 39 & 60 & 48 & 55 & 69 & 48 & 65 & 54.86 & 10.61 & 30 \\
\hline 32. SMITH \& NEPHEW & 54 & 37 & 48 & 43 & 67 & 48 & 48 & 49.29 & 9.41 & 30 \\
\hline 33. EXPERIAN & 74 & 70 & 73 & 72 & 61 & 73 & 44 & 66.71 & 10.95 & 30 \\
\hline 34. SEGRO & 23 & 55 & 31 & 46 & 28 & 31 & 52 & 38.00 & 12.73 & 32 \\
\hline 35. ROLLS- ROYCE & 2 & 13 & 31 & 18 & 21 & 31 & 35 & 21.57 & 11.75 & 33 \\
\hline 36. SERCO & 66 & 64 & 68 & 69 & 38 & 67 & 71 & 63.29 & 11.37 & 33 \\
\hline 37. BG & 33 & 29 & 31 & 31 & 1 & 35 & 26 & 26.57 & 11.63 & 34 \\
\hline 38. COMPASS & 33 & 40 & 53 & 50 & 44 & 52 & 67 & 48.43 & 10.88 & 34 \\
\hline 39. IMPERIAL TOBACCO & 65 & 49 & 31 & 47 & 45 & 42 & 31 & 44.29 & 11.67 & 34 \\
\hline 40. SEVERN TRENT & 39 & 55 & 31 & 45 & 64 & 35 & 66 & 47.86 & 14.01 & 35 \\
\hline 41. CAPITAL SHOPPING & 39 & 74 & 70 & 70 & 68 & 70 & 58 & 64.14 & 12.14 & 35 \\
\hline 42. BRITISH AIRWAYS & 14 & 30 & 26 & 30 & 26 & 26 & 50 & 28.86 & 10.76 & 36 \\
\hline 43. ANTOFAGASTA & 30 & 21 & 12 & 20 & 48 & 17 & 43 & 27.29 & 13.63 & 36 \\
\hline 44. BARRICK & 37 & 28 & 1 & 17 & 23 & 2 & 6 & 16.29 & 13.88 & 36 \\
\hline 45. JOHNSON MATTHEY & 56 & 19 & 19 & 21 & 26 & 21 & 23 & 26.43 & 13.26 & 37 \\
\hline 46. RBS & 71 & 67 & 59 & 65 & 34 & 59 & 38 & 56.14 & 14.45 & 37 \\
\hline 47. BRITISH LAND & 6 & 23 & 31 & 25 & 45 & 35 & 11 & 25.14 & 13.52 & 39 \\
\hline 48. SCHRODERS N/V & 25 & 53 & 53 & 52 & 51 & 52 & 64 & 50.00 & 11.89 & 39 \\
\hline 49. STANDARD LIFE & 46 & 64 & 48 & 58 & 56 & 50 & 25 & 49.57 & 12.51 & 39 \\
\hline 50. ABF & 11 & 48 & 31 & 48 & 8 & 40 & 39 & 32.14 & 16.55 & 40 \\
\hline 51. NATIONAL GRID & 17 & 57 & 31 & 51 & 28 & 40 & 57 & 40.14 & 15.56 & 40 \\
\hline 52. CARNIVAL & 1 & 5 & 12 & 5 & 42 & 10 & 19 & 13.43 & 13.89 & 41 \\
\hline 53. DIAGEO & 44 & 24 & 3 & 13 & 30 & 3 & 9 & 18.00 & 15.34 & 41 \\
\hline 54. INVESTEC & 46 & 20 & 43 & 27 & 61 & 42 & 49 & 41.14 & 13.73 & 41 \\
\hline
\end{tabular}




\begin{tabular}{lrrrrrrrrrr}
\hline COMPANY NAME & RQN & SQN I & SCI & TQLI & ACHI & SHI & MQM & MEAN & ST. & RANGE \\
& & & & & & & & & & \\
\hline 55. INTERCONTINENTAL & & & & & & & & & & \\
$\quad$ HOTELS & 14 & 11 & 12 & 10 & 53 & 12 & 40 & 21.71 & 17.38 & 43 \\
56. HOME RETAIL (ARGOS) & 23 & 66 & 43 & 57 & 57 & 46 & 47 & 48.43 & 13.78 & 43 \\
57. PRUDENTIAL & 58 & 62 & 62 & 64 & 24 & 62 & 68 & 57.14 & 14.92 & 44 \\
58. LLOYDS & 62 & 44 & 26 & 40 & 18 & 29 & 29 & 35.43 & 14.58 & 44 \\
59. CAPITA & 52 & 46 & 62 & 56 & 24 & 62 & 69 & 53.00 & 14.82 & 45 \\
60. J SAINSBURY & 39 & 21 & 9 & 19 & 42 & 21 & 55 & 29.43 & 16.18 & 46 \\
61. VEDANTA & 51 & 40 & 6 & 28 & 38 & 5 & 18 & 26.57 & 17.66 & 46 \\
62. RECKITT BENCKISER & 8 & 37 & 19 & 33 & 55 & 18 & 17 & 26.71 & 15.94 & 47 \\
63. SCOTTISH \& SOUTHERN & & & & & & & & & & \\
$\quad$ ENERGY & 9 & 10 & 48 & 14 & 49 & 50 & 56 & 33.71 & 21.45 & 47 \\
64. LOMIN & 53 & 17 & 6 & 12 & 38 & 8 & 14 & 21.14 & 17.57 & 47 \\
65. HSBC & 20 & 49 & 19 & 36 & 1 & 21 & 22 & 24.00 & 15.01 & 48 \\
66. TUI TRAVEL & 5 & 26 & 53 & 34 & 31 & 52 & 54 & 36.43 & 18.06 & 49 \\
67. WPP & 39 & 14 & 53 & 29 & 31 & 52 & 63 & 40.14 & 16.94 & 49 \\
68. REED ELSEVIER & 57 & 49 & 26 & 42 & 8 & 26 & 16 & 32.00 & 17.88 & 49 \\
69. LEGAL \& GENERAL & 18 & 18 & 31 & 24 & 1 & 35 & 51 & 25.43 & 15.74 & 50 \\
70. UNILEVER & 11 & 31 & 31 & 32 & 36 & 31 & 62 & 33.43 & 14.98 & 51 \\
71. BHP & 59 & 63 & 53 & 63 & 12 & 57 & 37 & 49.14 & 18.64 & 51 \\
72. AMEC & 62 & 49 & 62 & 61 & 13 & 66 & 36 & 49.86 & 19.28 & 53 \\
73. ANGLO AERICAN & 59 & 44 & 19 & 39 & 1 & 25 & 27 & 30.57 & 18.76 & 58 \\
74. GLAXOSMITHKLINE & 68 & 4 & 6 & 3 & 1 & 5 & 15 & 14.57 & 23.98 & 67 \\
\hline Average of Deviations & & & & & & & & & 11.92 \\
Min of Deviation & & & & & & & & & 3.87 \\
Max of Deviation & & & & & & & & & 23.98 \\
\hline
\end{tabular}

Note: The companies are ordered based on the values of RANGE: the lowest values of RANGE are at the top of column.

\section{Discussion and conclusion}

This paper empirically tests if the design of environmental sustainability disclosure quality measures makes a difference when comparing the quality scores across seven alternative reporting quality measures. To measure the quality of environmental sustainability disclosure, six widely used measures in the previous literature- both simple and compound measures- are compared with a new MQM that has been developed based on the quality perception of both preparers and users of corporate reporting. While the simple measures count the quantity of disclosure, the compound ones combine different dimensions in their attempt to measure the quality of environmental sustainability disclosure. These dimensions include: the quantity of disclosure (how much is disclosed), the content of disclosure (what and how is disclosed), the credibility of disclosure (adopting reporting guidelines and inclusion of an assurance statement), and the presentation of this disclosure (with text, tables, graphs or pictures) (see, Beattie et al., 2004; D'Amico et al., 2016; Michelon et al., 2015). The sample is comprised of the 74 companies in the FTSE100 index who produced CRRs in 2011. 
In line with the thematic content analysis of the quality of FTSE100 environmental disclosure, the statistical figures refute that the choice of selecting a specific measure for disclosure studies is inconsequential. It is shown that the selection of one quality measure over another can affect significantly the findings of the analysis. The findings of the current study offer empirical evidence concerning the significance of the design of a measure or metric to assess the quality of disclosure. Principally, quantity is necessarily but it is not enough to evaluate quality, other dimensions such as; measures, type of information, credibility, and presentation of this information should also be considered (Beretta and Bozzolan, 2008; Burritt and Christ, 2017; D’Amico et al., 2016; Helfaya and Kotb, 2016; Helfaya et al., 2018; Lokuwaduge and Heenetigala, 2017; Meng et al., 2014; Michelon et al., 2015; Tian et al., 2016; Urquiza et al., 2009). Further, the use of one particular metric can have a large effect on the rankings of companies. Even the use of similar measures (e.g., RQN and SQNI, or SHI and ACHI), produces deviations and differences. However, whilst both TQLI and MQM are both multi-dimensional measures; they still lead to significant differences in the quality scores and rankings they produced. It is contended that MQM is the best measure among the seven measures used, as it less subjective based on the views of both preparers and users and also covers a further two important aspects of information richness; credibility and presentation of this information (Helfaya et al., 2018). This strongly supports the assertion that the choice of a measure of disclosure quality might matter in this research area (Beattie et al., 2004; Urquiza et al., 2009).

Like all studies, our study is not without limitations. Because the data collection process used here to assess the quality of environmental sustainability disclosure using seven alternative measures is both difficult and labour intensive work, we employed a relatively small sample, so the extent to which the key findings cannot be generalised. However, our evidence on the different quality scores and rankings of the seven measures suggests that using compound measures (i.e., TQLI and MQM) which assess different dimensions that capture disclosure quality may be essential for future research in environmental disclosure. We also acknowledge that while the less subjective MQM presented here sought to capture a broader range of the possible and relevant characteristics and measures of disclosure quality, it has only been developed and empirically tested on the environmental sustainability disclosure, the use of such an MQM to assess social and financial disclosure quality could add to the literature and understanding of the assessment of corporate reporting quality. However, we believe that the MQM is a useful attempt to go beyond traditional author- 
based measures of disclosure. It provides evidence that assuming disclosure quantity and content as good proxies for disclosure quality might mislead the interpretation of findings; this MQM adds another two quality dimensions; the credibility and the style of the presentation of information disclosed. Another limitation is that we focus on only one year of data for one country, and further samples would be needed to discover if findings from other years or countries would be similar. It would also be worthwhile to compare and contrast the quality of corporate environmental reporting of UK branches of corporates to international branches in order to test the impact of local environmental regulations, media pressure, and society awareness of corporate environmental impact, etc., (Campbell et al., 2003; Garriga and Mele, 2004; KPMG, 2017).

We also consider one year at the end of the 2000-decade, which might be apparent as an old data. The year examined is at the end of an interesting decade which witnessed many corporate social and environmental crises and companies coming under examination for dubious accounting and governance practices (see, KPMG, 2017; Michelon et al., 2015). According to the recent KPMG Sustainability Survey (2017), global demand for transparency and accountability is high and therefore, we would anticipate more companies seeking to improve the quality of their sustainability reporting practices by adopting reporting guidelines, assurance services and the use more presentation tools as a response to this period of transparency and accountability crisis than might otherwise have been the case (see, also, Tian et al., 2016).

Previous studies outlined the significance of measurement units and scales and other problems related to designing measures/indices that might be investigated in future research (Burritt and Christ, 2017; Meng et al., 2014; Michelon et al., 2015). It would be beneficial for future research to test the effect that the detailed choice of disclosure measures has on the findings obtained and the consequences for corporate reporting (Urquiza et al., 2009). This study did not cover readability measures of reports (i.e., the language and style of writing used), and therefore measuring the readability of environmental disclosure is another avenue of future research. Last, but not least, our research focusses on one disclosure vehicle, the CRR, rather than annual reports, websites, or indeed the global trend to integrated reporting, and sustainability quality scores produced by professional Databases such as Carbon Disclosure Project Survey, Thomson Router, Bloomberg Platform and GRI Sustainability Disclosure Database. Further research will also need to address not only the 
measurement of the quality of the environmental sustainability disclosure in annual reports, integrated reports, websites, brochures, and to use the quality scores of reported sustainability information provided by Bloomberg and GRI Databases, but also the more complex holistic impact of such communication instruments as total corporate package.

\section{Acknowledgements:}

The authors would like to thank the editor (Professor Richard Welford) and the two anonymous reviewers of the journal for their constructive comments and valuable suggestions on earlier versions of the paper. The authors also acknowledge the financial support of the Faculty of Commerce, Damanhour University, Egypt. 


\section{References}

Al-Tuwaijri, S., Christensen, T., and Hughes, K. (2004). "The relations among environmental disclosure, environmental performance, and economic performance: A simultaneous equations approach." Accounting, Organizations and Society 29: 447 - 471.

Beattie, V., McInnes, B., and Fearnley, S. (2004). "A methodology for analysing and evaluating narratives in annual reports: a comprehensive descriptive profile and metrics for disclosure quality attributes." Accounting Forum 28: 205- 236.

Beattie, V., and Jones, M. (1992). "The use and abuse of graphs in annual reports: theoretical framework and empirical study." Accounting and Business Research 22(88): 291- 303.

Beattie, V., and Jones, M. (2001). "A six-country comparison of the use of graphs in annual reports." International Journal of Accounting 36: 196- 222.

Beck, A., Campbell, D., and Shrives, P. (2010). "Content analysis in environmental reporting research: Enrichment and rehearsal of the method in a British-German context." The British Accounting Review 42: 207-222.

Ben-Amar, W., and Chelli. (2018). "What drives voluntary corporate water disclosures? The effect of country-level institutions". Business Strategy and the Environment. DOI: $10.1002 /$ bse. 2227 .

Beretta, S., and Bozzolan, S. (2008). "Quality versus quantity: the case of forward-looking disclosure." Journal of Accounting, Auditing and Finance 23(3): Available online at: www.SSRN.com accessed 23/06/2009.

Bowen, H. (1953). Social responsibilities of the businessman. NewYork: Harper\& Row.

Brammer, S., and Pavelin, S. (2008). "Factors influencing the quality of corporate environmental disclosure." Business Strategy and the Environment 17(2): 120 - 136.

Burritt, R., and Christ, K. (2017). "The need for monetary information within corporate water accounting." Journal of Environmental Management 201: 72- 281.

Campbell, D., Craven, B., and Shrives, P. (2003). "Voluntary social reporting in three FTSE sectors: A comment on perception and legitimacy." Accounting, Auditing and Accountability Journal 16(4): 558 - 581.

Cavana,Y, Delahaye, L, and Sekaran, U. (2001). Applied Business Research: Qualitative and Quantitative Methods. Wiley: Queensland.

Cho, C., Roberts, R., and Patten, D. (2010). "The language of US corporate environmental disclosure." Accounting, Organizations and Society 35: 431- 443.

Cormier, D., Magnan, M., and Velthoven, B. V. (2005). "Environmental Disclosure Quality in Large German Companies: Economic Incentives, Public Pressures or Institutional Conditions?" European Accounting Review 14(1): 3- 39. 
D’Amico, E., Coluccia, D., Fontana, S., and Solimene, S. (2016). "Factors influencing corporate environmental disclosure." Business Strategy and the Environment 25: 178-192.

Friedman, M. (1962). Capitalism and freedom. Chicago: University of Chicago Press.

Garriga, E., and Mele', D. (2004). "Corporate social responsibility theories: Mapping the territory." Journal of Business Ethics 53: 51- 71.

Gray, R. (2006). "Does sustainability reporting improve corporate behaviour? Wrong question? Right time? "Accounting and Business Research 36: 65- 88.

Gray, R., Kouhy, R., and Lavers, S. (1995). "Methodological themes: Constructing a research database of social and environmental reporting by UK companies." Accounting, Auditing and Accountability Journal 8(2): 78- 101.

GRI (2002). Sustainability Reporting Guidelines 2002. Boston, Global Reporting Initiative. Available online at: www.globalreporting.org.

Guthrie, J., Cuganesan, S., and Ward, L. (2008). "Industry specific social and environmental reporting: The Australian Food and Beverage Industry." Accounting Forum 32: 1 - 15.

Hackston, D., and Milne, M. (1996). "Some determinants of social and environmental disclosures in New Zealand companies." Accounting, Auditing and Accountability Journal 9(1): 77- 108 .

Hammond, K., and Miles, S. (2004). "Assessing quality assessment of corporate social reporting: UK perspectives." Accounting Forum 28: 61 - 79.

Haque, F., and Ntim, C. (2018). "Environmental Policy, Sustainable Development, Governance Mechanisms and Environmental Performance." Business Strategy and the Environment 27: 415- 435.

Hassan, O. (2018). "The impact of voluntary environmental disclosure on firm value: Does organizational visibility play a mediation role?" Business Strategy and the Environment. DOI: 10.1002/bse.2217.

Healy, P., and Palepu, K. (2001). "Information asymmetry, corporate disclosure, and the capital markets: A review of the empirical disclosure literature." Journal of Accounting and Economics 31: 405- 440.

Helfaya, A. \& Kotb, A. (2016). "Environmental Reporting Quality: An Analysis of Global Credibility Initiatives", Ahmed, I, Handbook of Research on Green Economic Development: Initiatives and Strategies, (pp. 628-657). IGI Global Book.

Helfaya, A., Whittington, M., \& Alawattage, C. (2018), "Exploring the quality of corporate environmental reporting: Surveying Preparers' and Users' Perceptions", Accounting, Auditing and Accountability Journal. doi: 10.1108/AAAJ-04-2015-2023. 
Hopwood, A. (2009). "Accounting and the environment." Accounting, Organizations and Society 34: 433-439.

International Accounting Standards Board (2018). Conceptual Framework for Financial Reporting. IFRS Foundation, London.

Jensen, M.C. (2002) "Value maximisation, stakeholder theory, and the corporate objective function". Business Ethics Quarterly 12: 235- 256

Jizi, M. (2017). "The influence of board composition on sustainable development disclosure." Business Strategy and the Environment 26: 640- 655.

Jones, J., and Shoemaker, P. (1994). "Accounting narratives: A review of empirical studies of content and readability." Journal of Accounting Literature 13: 142- 184.

Kalu, J., Buang, A., and Aliagha, G. (2016). "Determinants of voluntary carbon disclosure in the corporate real estate sector of Malaysia." Journal of Environmental Management 182: 519- 524.

KPMG. (2017). The KPMG Survey of Corporate Responsibility Reporting. Netherlands: KPMG Sustainability Services. Retrieved from: http://www.kpmg.com.

Krippendorff, K. (2004). Content Analysis: An Introduction to its Methodology ( ${ }^{\text {nd }}$ edn), London: SAGE Publications.

Lee, Ki-H. (2017). "Does Size Matter? Evaluating Corporate Environmental Disclosure in the Australian Mining and Metal Industry: A Combined Approach of Quantity and Quality Measurement." Business Strategy and the Environment 26: 209- 223.

Lokuwaduge, CSDS., and Heenetigala, K. (2017). "Integrating environmental, social and governance (ESG) disclosure for a sustainable development: an Australian study." Business Strategy and the Environment 26: 438- 450.

Looser, S., and Wehrmeyer, W. (2015). "Doing well or doing good? Extrinsic and intrinsic CSR in Switzerland." UWF. Heidelberg: Springer. doi: 10.1007 / s00550-015-0360-9.

Meng, X., Zeng, S., Shi, J., Qi, G., and Zhang, Z. (2014). "The relationship between corporate environmental performance and environmental disclosure: An empirical study in China." Journal of Environmental Management 145: 357- 367.

Michelon, G., Pilonato, S., and Ricceri, F. (2015). "CSR reporting practices and the quality of disclosure: An empirical analysis”, Critical Perspectives on Accounting 33: 59-78.

Milne, M., and Adler, R. (1999). "Exploring the Reliability of Social and Environmental Disclosures Content Analysis." Accounting, Auditing and Accountability Journal 12(2): 237-256.

Patten, D., \& Zhao, N. (2014). "Standalone CSR reporting by U.S. retail companies." Accounting Forum 38(2): 132-144. 
Phillips, R. (2003). Stakeholder theory and organizational ethics. San Francisco: BerrettKoehler Publishers.

Radu, C., and Francoeur, C. (2017). "Does Innovation Drive Environmental Disclosure? A New Insight into Sustainable Development." Business Strategy and the Environment 26: 893- 911.

Smith, A. (1776). An Inquiry into the Nature and Causes of the Wealth of Nations. Wordsworth Editions (2012), UK.

Tian, X-L., Guo, Q-G., Han, C., and Ahmed, N. (2016). "Different extent of environmental information disclosure across Chinese cities: Contributing factors and correlation with local pollution." Global Environmental Change 39: 244- 257.

Toms, J. (2002). "Firm Resources, Quality Signals, and the Determinants of Corporate Environmental Reputation: Some UK Evidence." British Accounting Review 34: 257- 282.

Unerman, J. (2000). "Methodological issues Reflections on quantification in corporate social reporting content analysis." Accounting, Auditing \&Accountability Journal 13(5): 667 - 680.

Urquiza, F., Abed, M., and Trombetta, M. (2009). "Disclosure indices design: Does it make a deference?" Spanish Accounting Review 12(2): 253- 278.

van Staden, C., and Hooks, J. (2007). "A comprehensive comparison of corporate environmental reporting and responsiveness." The British Accounting Review 39: 197 - 210. 